DOI: $10.12731 / 2070-7568-2018-2-96-110$

УДК 338.012

\title{
РЕЗУЛЬТАТИВНОСТЬ СМК \\ КАК ФАКТОР ЭКОНОМИЧЕСКОЙ СОСТОЯТЕЛЬНОСТИ ПТИЦЕВОДЧЕСКИХ ПРЕДПРИЯТИЙ
}

\author{
Акопян А.Г., Валдохина С.И., Ройтер Л.М., \\ Зазыкина Л.А., Фролова Т.А.
}

В статье рассматривается вопрос взаимосвязи системы менеджмента качества (СМК) и экономической состоятельности птицеводческих предприятий.

Целью исследования является установление взаимосвязи результативности СМК и экономической состоятельности хозяйствующих субъектов отрасли птицеводства.

Методы или методология проведения работы: методы системного, структурного и сравнительного анализа, методы группировок и графической иллюстрации, позволяющих выявить причинно-следственные связи экономической состоятельности птицеводческих предприятий, анализ литературы по исследуемой проблеме.

Результаты: Выполнен анализ современного состояния отрасли птицеводства. Установлены причины снижения экономической состоятельности хозяйствующих субъектов отрасли и освещение возможных путей их решения. Подчеркивается, что базисом повышения экономической состоятельности птицеводческих предприятий в современных экономических условиях является полное удовлетворение запросов отечественных и зарубежных потребителей птицеводческой продукиии в соответствиис требованиями, предъявляемыми кее качеству. Качество птицепродукции рассматривается с позищий интегратора результативности бизнес-процессов птицеводческого предприятия. Предлагается методика оченки результативности системы менеджмента качества применительно к отрасли птицеводства с адаптаџией ее на конкретном предприятии и достигнутыми положительными эффектами. 
Область применения результатов: результаты исследования востребованы департаментами сельского хозяйства, а также специалистами птицеводческих предприятий.

Ключевые слова: птицеводство; система менеджмента качества; безопасность пищевой продукиии; экономическая состоятельность; результативность.

\title{
THE EFFECTIVENESS OF THE QMS AS A FACTOR OF ECONOMIC STATUS OF POULTRY ENTERPRISES
}

\author{
Akopyan A.G., Valdohina S.I., Roiter L.M., \\ Zazykina L.A., Frolova T.N.
}

The article dwells to the relationships between the quality management system and the economic viability of poultry enterprises.

Purpose: is to establish the relationship between the effectiveness of QMS and the economic viability of the economic sector of poultry.

Methodology: includes methods of system and structural analysis, grouping and comparative analysis, as well as graphic illustration that allows to identify the cause-effect relationship of poultry farms' economic viability and literature task-analysis.

Results: The current state of the poultry industry is analyzed. The reasons of sector's enterprises economic soundness reducing are shown as wel as the possible ways out. In the modern economical conditions the basis to raise the economical soundness poultry business is to fully satisfy the quality requirements of customers inland and abroad, is underlined at the article. The poultry production quality is considered as an integrator of poultry subject effectiveness' integrator. There is a methodic to estimate the QMS of a poultry business, positively adapted on a concrete enterprise.

Practical implications: Our practical implications are useful for employees of poultry farms, agricultural enterprises.

Keywords: poultry; quality management system; food safety; economic viability; efficiency. 


\section{Введение}

Птицеводство является лидирующей отраслью животноводства в России. Ее динамичность характеризуется приростными значениями соответствующих показателей за анализируемый период, так, например, за январь-февраль 2018 года производство птицы на убой в живом весе в сельскохозяйственных организациях составило 1,0 млн тонн, что на 7,2\% больше, чем годом ранее (2017 г. - 940,9 тыс. тонн). В 2017 году по всем категориям хозяйств произведено 4940 тыс. т мяса птицы в убойной массе, что на 7\% больше уровня 2016 года. Темп прироста в 2017 г. по производству мяса птицы в убойной массе составил $6,9 \%$, по производству свинины в убойной массе $-5,01 \%$, по производству КРС в убойной массе $-0 \%$. Что касается производства яиц, то за период январь - февраль 2018 г. 5,8 млрд штук, что на 1,5\% больше, чем в 2017 г. - 5,7 млрд штук, в этом же периоде. За весь же 2017 год производство яиц составило 44,8 млрд. шт., это на 1,2 млрд. шт. или на 2,8\% больше уровня 2016 года. Наряду с этим высоким потенциалом анализируемой нами отрасли обусловленными как ростом объемов производства, так и расширением ее ассортимента. Ассортимент мяса птицы в 2017 году составил следующие показатели: Тушки (охлажденные и замороженные) - 35\%, натуральные полуфабрикаты в панировке и без - $45 \%$, готовые к употреблению $20 \%$.

На фоне изменений в экономике страны усиливается необходимость внедрения инновационных разработок, стратегической целью которых является повышение экономической состоятельности птицеводческих предприятий [3, с. 6]. К числу научно-практических исследований, касающихся вопроса взаимосвязи системы менеджмента качества и экономической состоятельности птицеводческих предприятий следует отнести труды отечественных и зарубежных ученых, а также специалистов в данной области (таких как С.М. Вдовин, Н.В. Замятина, И.Д. Котляров, В. Комиссаров [1, с. 181,17 , с. 78,16 , с. 63,18 , с. 76$]$. Интегрируя различные точки зрения ученых по сущностной характеристике категории экономической состоятельности необходимо сделать акцент на двух ее 
составляющих, а именно потенциале предприятия и его конкурентоспособности. Причем данный понятийный аппарат целесообразно рассматривать применительно к современным экономическим условиям с позиций наращивания финансового потенциала предприятия, ключевым фактором которого являются результативность СМК. Одновременно изучение обозначенной проблемы носит разрозненный характер, отсутствует системность аналитики взаимообусловленности системы менеджмента качества и экономической состоятельности интересующей нас отрасли.

Сегодня инновационные решения в отрасли направлены на совершенствование совокупности бизнес-процессов, результативность которых суммарно характеризуются выпуском птицеводческой продукции согласно требованиям соответствия ее качества, международным стандартам посредством разработки СМК применительно к отрасли птицеводства [1, с. 170].

Следовательно, аналитическое исследование взаимосвязи СМК и экономической состоятельности птицеводческих предприятий актуально.

\section{Материалы и методы}

Исследование проводилось в определенной последовательности, сущность которой заключается в оценке отрасли птицеводства через изучение причин снижения эффективности ее функционирования и выделение лидирующих хозяйствующих субъектов с обоснованием критериев (максимального удовлетворения запросов отечественных и зарубежных потребителей их продукцией, через механизм адаптации СМК в птицеводстве), позволивших занять эту нишу.

В работе применялись общенаучные методы анализа и синтеза, методы анализа финансово-хозяйственной деятельности предприятия, а также методы многокритериальной оценки.

\section{Результаты}

Анализ коммерческих корпоративных организаций за 2016 год показал, что из общего их числа 19,6 \% были ликвидированы, а на 
стадии ликвидации находилось 10,2\% организаций. Данная ситуация обусловлена рядом причин, к числу которых следует отнести закредитованность предприятий, превышение темпов роста себестоимости продаж над темпами роста выручки от реализуемой продукции, снижением платежеспособного спроса населения. Реально располагаемые денежные доходы сократились за 2014-2016 гг. на 10\%. Одновременно следует добавить существенную инфляцию (индекс роста потребительских цен за период 2014-2016 гг. составил 133,3\%, индекс потребительских цен на продовольствие - 139,5\%), оборот розничной торговли за этот же период сократился на $12 \%$.

Относительно решения проблемы диспаритета цен в птицеводстве целесообразно разработать систему государственных гарантий для сельхозпроизводителей, которые включают в себя выплаты в случае неблагоприятных последствий от существенного роста цен и тарифов. Проблема закредитованности птицеводческих предприятий может быть решена на основе комплексного подхода, взаимоучитывающего интересы субъектов кредитной системы: заемщиков, кредитов и государства. А именно:

- со стороны государства необходимо увеличить лимиты бюджетных средств, выделяемое на льготное кредитование;

- расширить перечень банков в кредитовании производства птицепродукции. В настоящее время значительную часть в кредитовании птицеводства приходится на долю банков с государственной продержкой;

- минимизация налогового обременения для производителей

- усиление государственной поддержки при реализации форм проектного финансирования, а также не связанной поддержки доходности птицеводческих предприятий.

В рамках решения данной проблемы требуется понимание, что уровень кредитования должен соответствовать задачам импортозамещения и развития экспортного потенциала, стоящими перед отраслью птицеводства.

Одновременно к числу экономически состоятельных можно отнести лишь 10,6\% коммерческих корпоративных птицеводческих 
организации. Надо отметить, что данные предприятия имеют рентабельность активов более $20 \%$. Такой уровень рентабельности обусловлен привлечением как кредитов и займов по льготной процентной ставке, субсидированных бюджетами федерального и регионального уровней, так объемом, ассортиментом, качеством производимой ими птицеводческой продукции [3, с. 433]. Как правило, эти предприятия, относятся к ТОП-20 с объемами производства яиц и мяса птицы практически на уровне 60 и $80 \%$ общего баланса отрасли $[2$, с. 6]. Их перечень представлен на рисунке 1.

Вышеприведенные хозяйствующие субъекты отрасли основной миссией своей деятельности считают полное удовлетворение запросов отечественных и зарубежных потребителей их продукции как за счет ее качества, через механизм адаптации системы менеджмента качества на основе разработок ФНЦ «ВНИТИП» РАН, так и расширения ассортиментного портфеля.

Эти разработки включают интегрированную модель СМК и методику оценки ее результативности на птицеводческих предприятиях.

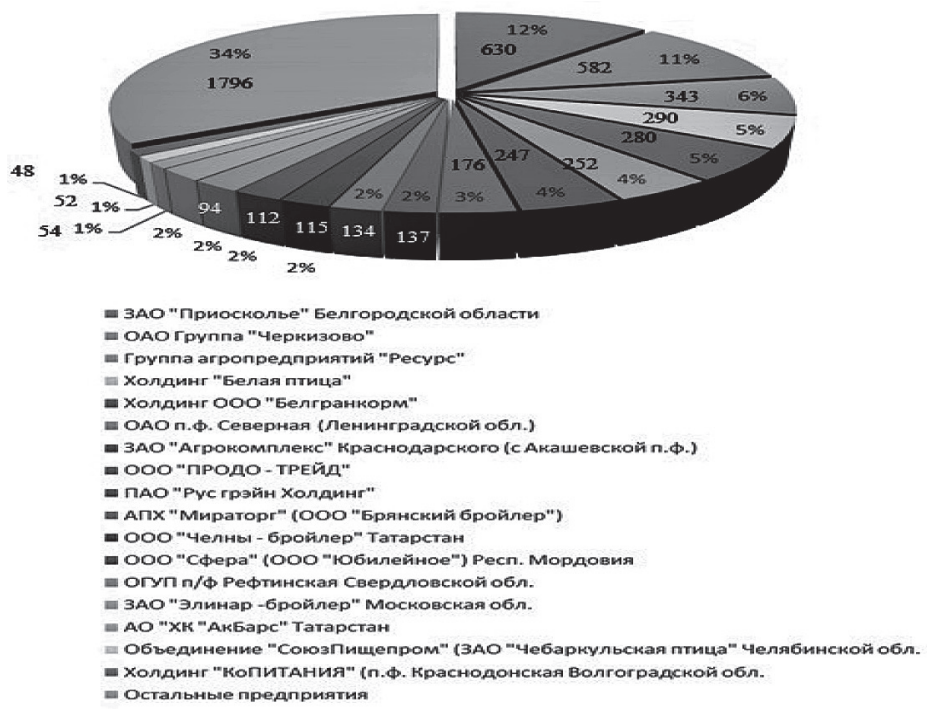

Рис. 1. ТОП крупных организаций по производству мяса птицы, \% (составлено на основании источника $[2$, с. 6]) 


\section{Результаты исследований}

Научные разработки ФНЦ «ВНИТИП» РАН по системе менеджмента качества были разосланы по хозяйствующим субъектам отрасли одновременно с анкетой об эффективности их внедрения на птицеводческих предприятиях [12, с. 11].

Для оценки степени соответствия действующей СМК предприятия требованиям ISO провели ее обследование. При этом тщательно изучили действующую организационную структуру птицефабрики и организационно-распорядительные документы, регламентирующие систему качества [9, с. 60].

Данные анкетирования свидетельствуют о положительном эффекте внедрения разработанных методик системы менеджмента качества применительно к отрасли птицеводства (табл. 1).

Таблица 1.

Результативность внедрения системы менеджмента качества на птицеводческих предприятиях (составлено на основании источника [12])

\begin{tabular}{|c|l|c|}
\hline № & \multicolumn{1}{|l|}{ Достигнутый результат при внедрении СМК } & $\begin{array}{c}\text { Процент опрошенных } \\
\text { руководителей, под- } \\
\text { твердивших достиже- } \\
\text { ние результата, } \%\end{array}$ \\
\hline 1. & Рост объемов птицепродукции & 85,0 \\
\hline 2. & $\begin{array}{l}\text { Рост удовлетворенности потребителей птицепро- } \\
\text { дукции }\end{array}$ & 72,0 \\
\hline 3. & Увеличение доли рынка птицеводческой продукции & 80,0 \\
\hline 4. & $\begin{array}{l}\text { Расширение ассортиментного портфеля выпускае- } \\
\text { мой птицепродукции }\end{array}$ & 75,0 \\
\hline 5. & $\begin{array}{l}\text { Рациональное ресурсов при производстве птице- } \\
\text { водческой продукции }\end{array}$ & 82,0 \\
\hline 6. & $\begin{array}{l}\text { Снижение рекламаций и претензий к качеству пти- } \\
\text { цеводческой продукции }\end{array}$ & 60,0 \\
\hline 7. & Обеспечение экономической состоятельности & 85,0 \\
\hline
\end{tabular}

Согласно мнению специалистов хозяйствующих субъектов отрасли, адаптация этих разработок способствовала, не только улучшению качественных параметров производимой птицеводческой продукции, но и повышению их экономической состоятельности $[13$, с. 520,11, с. 41$]$. 
Практическая реализация оценки результативности научной разработки по СМК была осуществлена на ОАО «Волжанин», основным видом деятельности которого является производство товарного яйца. Базовой основой внедрения СМК на анализируемом предприятии является разработанная интегрированная модель СМК, представленная на рисунке 2 .

Оценка результативности СМК осуществлялась по соответствующей методике с определенной детализацией:

- индивидуальная оценка каждого бизнес-процесса (подпроцесса) соответствующих блоков;

- расчет консолидированного показателя по бизнес-процессам и блокам бизнес-процессов [8, с. 13];

- определение уровня результативности и сводного уровня запаса прочности бизнес-процессов (блоков бизнес-процессов) СМК.

Оценка осуществлялась по 3-балльной шкале с учетом нулевого уровня. Максимальные значения (количество баллов, уровень рентабельности) рассчитаны исходя из предельных величин и значимости.

Расчет величины результативности СМК характеризуется как абсолютной величиной (балл), так и относительной $(\%)$ [15, с. 61].

Математическая модель исчисления абсолютного максимального значения результативности СМК имеет следующий вид [12, c. 17,14, c. 65$]$ :

$$
\mathrm{y}_{\mathrm{R}}^{\mathrm{max}}=\sum_{\mathrm{i}=1}^{\mathrm{k}} \sum_{\mathrm{j}=1}^{\mathrm{a}}\left(\mathrm{K}_{\mathrm{ij}} \times \beta_{\mathrm{ij}}\right),
$$

где: $\mathrm{Y}_{\mathrm{R}}^{\max }$ - максимальный показатель результативности СМК, балл;

$\mathrm{K}_{\mathrm{ij}}$ - количественное значение $\mathrm{i}$-того критерия результативности j-того подпроцесса СМК, балл;

$\beta_{\mathrm{ij}}$ - весовой коэффициент i-того критерия оценки результативности ј-того бизнес-процесса (подпроцесса) в СМК, в долях;

$\mathrm{i}=1,2, \ldots, \mathrm{k}$ - количество критериев оценки результативности бизнес-процессов;

$\mathrm{j}=1,2, \ldots, \mathrm{a}-$ общее количество подпроцессов в СМК. 


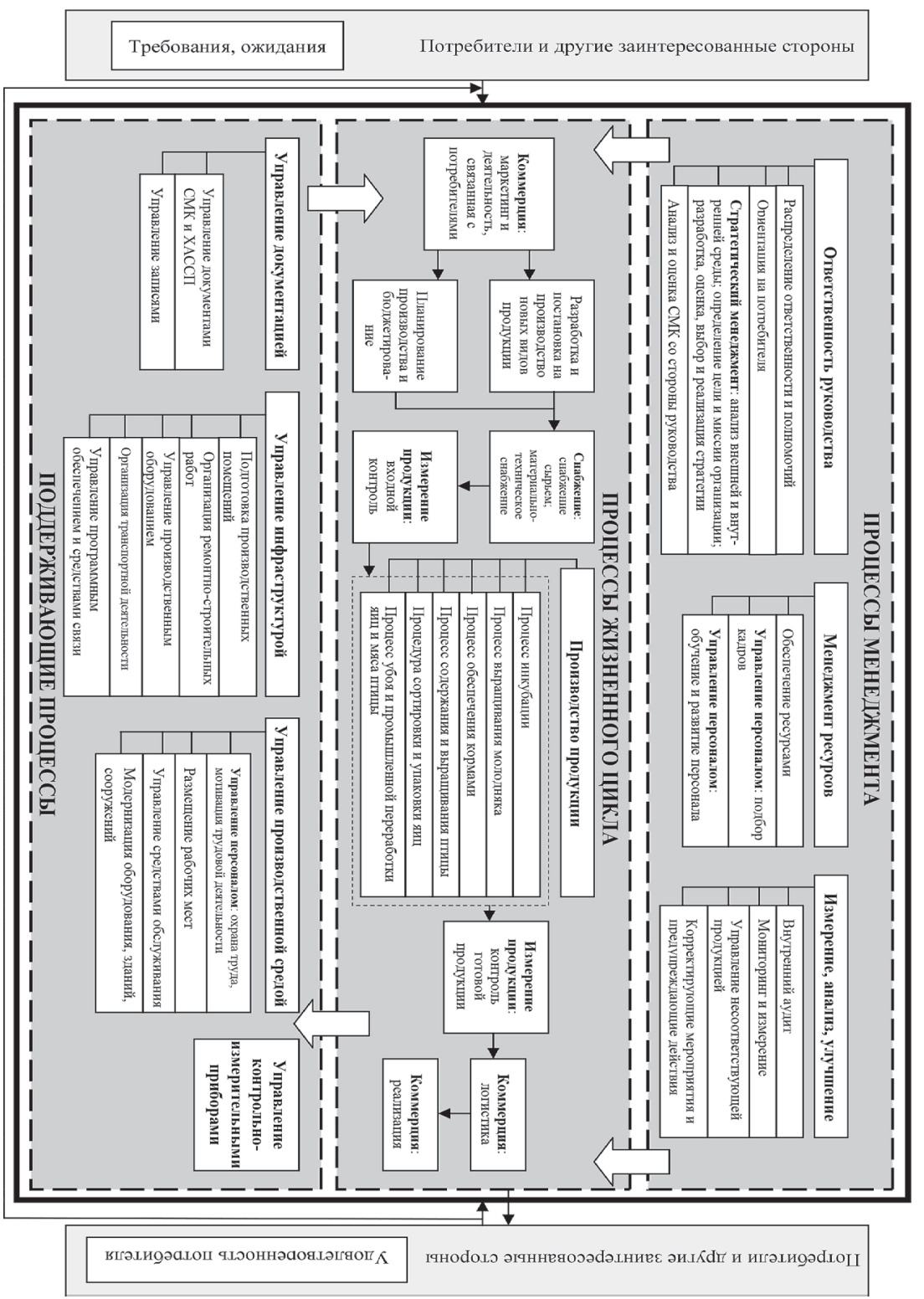

Рис. 2. Интегрированная модель системы менеджмента качества птицеводческого предприятия (составлено на основании источника [12]) 
Уровень результативности бизнес-процессов и по блокам бизнеспроцессов в составе СМК рассчитывается по формуле [10, с. 21]:

$$
\mathrm{y}_{\text {св. } \Sigma \mathrm{j}}=\sqrt{\sum_{\mathrm{i}=1}^{\mathrm{k}} \sum_{\mathrm{j}=1}^{\mathrm{a}}\left(\mathrm{y}_{\mathrm{Rj}}^{\mathrm{max} 2} \times \beta_{\mathrm{ij}}^{2}\right)}-\sqrt{\sum_{\mathrm{i}=1}^{\mathrm{k}} \sum_{\mathrm{j}=1}^{\mathrm{a}}\left(\mathrm{y}_{\mathrm{Rj}}^{2} \times \beta_{\mathrm{ij}}^{2}\right)},
$$

где: $\mathrm{y}_{\text {св.гј }}$ - обобщенный показатель уровня запаса между максимальным уровнем результативности СМК предприятия и его фактическим уровнем;

$\mathrm{y}_{\text {св.j }}$ - обобщенный показатель уровня запаса между максимальным уровнем результативности бизнес-процессов (подпроцессов) и его фактическим уровнем;

$\mathrm{y}_{\text {св.с }}$ - обобщенный показатель уровня запаса между максимальным уровнем результативности бизнес-процессов

Итоговые результаты по всей совокупности бизнес-процессов, а также уровни результативности и запаса прочности СМК ОАО «Волжанин» отражена в табл. 3, 4. [12, с. 143-144, 4, с. 250].

Таблица 3.

Сводные данные по результативности бизнес-процессов СМК (составлено на основании источника [12])

\begin{tabular}{|c|c|c|c|c|}
\hline $\begin{array}{c}\text { № } \\
\text { п/п }\end{array}$ & Бизнес- процесс & $\begin{array}{c}\text { Весов. коэф. } \\
\text { оценка }\end{array}$ & $\begin{array}{c}\text { Консолид. } \\
\text { показатель }\end{array}$ & Отклонение \\
\hline 1 & Процессы менеджмента & 41,70 & 2,78 & 0,14 \\
\hline 2 & Процессы жизненного цикла & 175,4 & 2,70 & 0,06 \\
\hline 3 & Поддерживающие процессы & 47 & 2,35 & $-0,29$ \\
\hline 4 & $\begin{array}{c}\text { Вся совокупность бизнес- } \\
\text { процессов системы } \\
\text { менеджмента качества }\end{array}$ & 264,10 & 2,64 & 0,00 \\
\hline
\end{tabular}

Таблица 4.

Оценка уровня результативности бизнес-процессов в системе менеджмента качества (составлено на основании источника [12])

\begin{tabular}{|c|c|c|c|}
\hline $\begin{array}{c}\text { № } \\
\text { п/п }\end{array}$ & Бизнес- процесс & $\begin{array}{c}\text { Уровень } \\
\text { результативности, \% }\end{array}$ & $\begin{array}{c}\text { Сводный уровень } \\
\text { запаса прочности }\end{array}$ \\
\hline 1 & Процессы менеджмента & 92,67 & 0,56 \\
\hline 2 & Процессы жизненного цикла & 89,95 & 2,43 \\
\hline 3 & Поддерживающие процессы & 78,33 & 3,45 \\
\hline 4 & $\begin{array}{c}\text { Вся совокупность бизнес- } \\
\text { процессов системы } \\
\text { менеджмента качества }\end{array}$ & 88,03 & 3,58 \\
\hline
\end{tabular}




\section{Обсуждение}

Исходя из данных представленных в таблице 4, следует отметить, что по уровню результативности, анализируемую совокупность бизнес-процессов СМК ОАО «Волжанин» следует отнести к группе с высокой результативностью (свыше 88,03\%). Результативность внедрения интегрированной системы менеджмента качества на исследуемом предприятии свидетельствует о положительной динамике продаж $(37,1 \%)$, продуктивности птицы $(1,3 \%)$, выхода яиц и мяса птицы высшей и первой категорий $(2,2 \%)$, уровень рентабельности продукции на этом предприятии выше среднеотраслевой в 1,3 раза.

При этом можно говорить об укреплении доверия потребителей к качеству и безопасности выпускаемой продукции ОАО «Волжанин» и его имиджа, который подтверждается увеличением соответствующей доли рынка на 5,2\% и ростом индекса удовлетворенности потребителей, выпускаемой данной компанией птицеводческой продукцией [7, с. 20].

\section{Заключение}

Аналитика, изучаемого вопроса позволяет говорить о тесной взаимосвязи результативности системы менеджмента качества и экономической состоятельности птицеводческих предприятий [10, с. 7].

Результативность внедрения системы менеджмента качества и безопасности пищевых продуктов на основе методической базы, разработанной ФНЦ «ВНИТИП» РАН подтверждена соответствующими документами по системе СМК и положительными эффектами, достигнутыми в данном направлении, а именно:

- обеспечением выпуска безопасной птицеводческой продукции стабильного качества за счет системного мониторинга на всех этапах производства и продвижения продукции до потребителя;

- укреплением доверия потребителей к качеству и безопасности выпускаемой продукции, что усилило имидж предприятия;

- расширением сеть потребителей продукции;

- повышением конкурентоспособности птицепродукции;

- минимизацией технологических и коммерческих рисков при производстве и реализации птицепродукции. 


\section{Список литературы}

1. Андерсен Б. Бизнес-процессы. Инструменты совершенствования / Пер. с англ. С.В. Ариничева / Науч. ред. Ю. П. Адлер. М.: РИА «Стандарты и качество», 2003. 272 с. Бобылева Г.А. Задача птицеводческой отрасли - реализация Доктрины продовольственной безопасности Российской Федерации // Птица и птицепродукты. 2016. №5. С. 6-8.

2. Бобылева Г.А. Состояние и перспективы развития отечественного птицеводства // Агропромышленный комплекс. 2014. С. 431-436.

3. Величко А.В. Методы повышения продуктивности птицы, качества пищевых яиц и яичных продуктов при использовании высокопродуктивных кроссов кур: диссертация ... доктора сельскохозяйственных наук: 06.02.04. Сергиев Посад, 2010. 283 с.

4. Вдовин С.М. Система менеджмента качества организации: Учеб. пособие / С.М. Вдовин, Т.А. Салимова, Л.И. Бирюкова. М.: ИНФРА-М. 2012. $301 \mathrm{c}$.

5. Гущин В.В. Международные стандарты на птицепродукты // Птицеводство. 2009. № 7. С. 42.

6. Доктрина продовольственной безопасности Российской Федерации нуждается в совершенствовании / И.Г. Ушачев, Л.В. Бондаренко, А.Ф. Серков и др. // АПК: экономика, управление. 2015. № 9. С. 3-12.

7. Замятина Н.В. Управление бизнес-процессами птицеводческого предприятия на основе внедрения системы менеджмента качества и ХАССП// Птица и птицепродукты. 2014 №1. С. 19-22.

8. Комиссаров В. Реализация системы менеджмента качества (СМК) / В. Комиссаров, А. Сизов // Птицеводство. 2011. № 1. С. 13-20.

9. Красноярцев Г.В. Ускорить процесс внедрения системы менеджмента качества в птицеводстве // Птица и птицепродукты. 2014. №4. С. 59-61.

10. Менеджмент в пищевой промышленности. Монография / Е.Б. Гаффорова [и др.]. М.: Издательство «Академия Естествознания», 2011.

11. Мерзликина Г.С. Экономическая состоятельность: оценка и управление // Вестник АГТУ. Сер.: Экономика. 2011. №1. С. 40-44.

12. Методика оценки результативности системы менеджмента качества на птицеводческих предприятиях: методическое руководство / Ройтер Л.М. [и др.]. Сергиев Посад. 2016. 181 с. 
13. Промышленное птицеводство. Монография / Под общей ред. В.И. Фисинина. М.: ООО «Лика», 2016. С. 508-531.

14. Ройтер Л.М., Акопян А.Г. Оценка результативности системы менеджмента качества в птицеводстве // Птица и птицепродукты. 2016. №4. C. 64-68.

15.Zaharias, Panagiotis and Pappas, Christopher "Quality Management of Learning Management Systems: A User Experience Perspective”, Current Issues in Emerging eLearning. 2016. Vol. 3: Iss. 1, Article 5, pp. 60-84.

16. Заостровцев А.П. Реакция на контрсанкции: «Мы за ценой не постоим...» // Общественные науки и современность. 2017. № 5. С. 46-60.

17. Котляров И.Д. Развитие экспорта российской сельскохозяйственной продукции на основе сетевого сотрудничества в АПК // Экономика сельского хозяйства России. 2018. № 2. С. 76-84.

\section{References}

1. Andersen B. Biznes-protsessy. Instrumenty sovershenstvovaniya [Business processes. Improvement tools] / Trans. with English S.V. Arinicheva. M.: RIA "Standards and Quality", 2003. 272 p.

2. Bobyleva G.A. Sostoyanie i perspektivy razvitiya otechestvennogo ptitsevodstva [State and prospects of development of domestic poultry farming]. Agropromyshlennyy kompleks [Agroindustrial complex]. 2014, pp. 431-436.

3. Velichko A.V. Metody povysheniya produktivnosti ptitsy, kachestva pishchevykh yaits $i$ yaichnykh produktov pri ispol'zovanii vysokoproduktivnykh krossov kur [Methods of increasing the productivity of poultry, the quality of food eggs and egg products when using highly productive cross-country chickens]: the thesis ... Doctors of Agricultural Sciences: 06.02.04. Sergiev Posad, 2010. 283 p.

4. Vdovin S.M., Salimova T.A., Biryukov L.I. Sistema menedzhmenta kachestva organizatsii [The organization's quality management system]. M.: INFRA-M. 2012. 301 p.

5. Gushchin V.V. Mezhdunarodnye standarty na ptitseprodukty [International standards for poultry products]. Ptitsevodstvo [Poultry]. 2009. № 7. P. 42.

6. Ushachev I.G., Bondarenko L.V., Serkov A.F., etc. Doktrina prodovol'stvennoy bezopasnosti Rossiyskoy Federatsii nuzhdaetsya v sovershenstvovanii [The doctrine of food security of the Russian Federation needs 
to be improved]. APK: ekonomika, upravlenie [AIC: economy, management]. 2015. № 9, pp. 3-12.

7. Zamyatina N.V. Upravlenie biznes-protsessami ptitsevodcheskogo predpriyatiya na osnove vnedreniya sistemy menedzhmenta kachestva i KhASSP [Management of business processes of a poultry farm based on the introduction of a quality management system and HACCP]. Ptitsa i ptitseprodukty [Bird and poultry products]. 2014 №1, pp. 19-22.

8. Komissarov V., Sizov A. Realizatsiya sistemy menedzhmenta kachestva (SMK) [Implementation of the quality management system (QMS)]. Ptitsevodstvo [Poultry]. 2011. № 1, pp. 13-20.

9. Krasnoyartsev G.V. Uskorit' protsess vnedreniya sistemy menedzhmenta kachestva $\mathrm{v}$ ptitsevodstve [To speed up the process of introducing a quality management system in poultry farming]. Ptitsa i ptitseprodukty [Bird and poultry products]. 2014. №4, pp. 59-61.

10. Menedzhment $v$ pishchevoy promyshlennosti [Management in the food industry]. Monograph / E.B. Gafforova [and others]. M.: Publishing house "Academy of Natural Science", 2011.

11. Merzlikina G.S. Ekonomicheskaya sostoyatel'nost': otsenka i upravlenie [Economic viability: assessment and management]. Vestnik AGTU. Ser.: Ekonomika [Vestnik ASTU. Economics]. 2011. № 1, pp. 40-44.

12. Roiter L.M., etc. Metodika otsenki rezul tativnosti sistemy menedzhmenta kachestva na ptitsevodcheskikh predpriyatiyakh: metodicheskoe rukovodstvo [Methodology for assessing the effectiveness of the quality management system at poultry enterprises: a methodical guide]. Sergiev Posad, 2016. 181 p.

13. Promyshlennoe ptitsevodstvo [Industrial poultry farming]. Monograph. M.: OOO "Lika", 2016, pp. 508-531.

14. Royter L.M., Akopyan A.G. Otsenka rezul'tativnosti sistemy menedzhmenta kachestva $\mathrm{v}$ ptitsevodstve [Assessment of the effectiveness of the quality management system in poultry farming]. Ptitsa i ptitseprodukty [Bird and poultry products]. 2016. №4, pp. 64-68.

15.Zaharias, Panagiotis and Pappas, Christopher "Quality Management of Learning Management Systems: A User Experience Perspective”, Current Issues in Emerging eLearning. 2016. Vol. 3: Iss. 1, Article 5, pp. 60-84.

16.Zaostrovtsev A.P. Reaktsiya na kontrsanktsii: «My za tsenoy ne postoim...» [The reaction to the counterforce: "We will not stand behind the 
price ...”]. Obshchestvennye nauki i sovremennost' [Social sciences and modernity]. 2017. № 5, pp. 46-60.

17. Kotlyarov I.D. Razvitie eksporta rossiyskoy sel'skokhozyaystvennoy produktsii na osnove setevogo sotrudnichestva v APK [Development of exports of Russian agricultural products on the basis of network cooperation in the agroindustrial complex]. Ekonomika sel'skogo khozyaystva Rossii [Economics of Agriculture of Russia]. 2018. № 2, pp. 76-84.

\section{ДАННЫЕ ОБ АВТОРАХ}

Акопян Амаяк Григорьевич, Валдохина Светлана Ивановна, Ройтер Лия Моисеевна, Зазыкина Любовь Александровна, Фролова Татьяна Анатольевна

Федеральное государственное бюджетное научное учреждение Федеральный научный иентр «Всероссийский научноисследовательский и технологический институт птицеводства» Российской академии наук (ФНЦ «ВНИТИП»РАН) ул. Птицеградская, 10, г. Сергиев Посад, Московская обл., 141311, Российская Федерация sunny.2012@ya.ru

\section{DATA ABOUT THE AUTHORS}

Akopyan Amayak Grigorevich, Valdohina Svetlana Ivanovna, Roiter Liya Moiseevna, Zazykina Lyubov Aleksandrovna, Frolova Tatyana Anatolevna

Federal State Budget Scientific Institution Federal Scientific Center "All-Russian Research and Technological Poultry Institute" of Russian Academy of Sciences

10, Pticegradskaya Str., Sergiev Posad, Moscow Region, 141311, Russian Federation sunny.2012@ya.ru 